\title{
Correction to: Fault detection in distillation column using NARX neural network
}

\author{
Syed A. Taqvi ${ }^{1,2} \cdot$ Lemma Dendana Tufa $^{1} \cdot$ Haslinda Zabiri ${ }^{1} \cdot$ Abdulhalim Shah Maulud $^{1}$. \\ Fahim Uddin ${ }^{1}$
}

Published online: 30 May 2021

(C) Springer-Verlag London Ltd., part of Springer Nature 2021

\section{Correction to: Neural Computing and Applications https://doi.org/10.1007/s00521-018-3658-z}

The original version of this article contained errors in the affiliation list. We found that the second affiliation of $1 \mathrm{st}$ Author "Syed A. Taqvi" is missing. The missed affiliation is given below:

Syed A. Taqvi ${ }^{1,2}$

${ }^{1}$ Chemical Engineering Department, Universiti Teknologi PETRONAS, 32610 Seri Iskandar, Perak Darul Ridzuan, Malaysia
${ }^{2}$ Department of Chemical Engineering, NED University of Engineering and Technology Karachi, 75270, Pakistan.

These errors have now been corrected in the HTML and PDF versions of the Article.

Publisher's Note Springer Nature remains neutral with regard to jurisdictional claims in published maps and institutional affiliations.

The original article can be found online at https:// doi.org/10.1007/s00521-018-3658-z.

Lemma Dendana Tufa

lemma_dendena@utp.edu.my

1 Chemical Engineering Department, Universiti Teknologi PETRONAS, 32610 Perak Darul Ridzuan, Seri Iskandar, Malaysia

2 Department of Chemical Engineering, NED University of Engineering and Technology, Karachi 75270, Pakistan 